\title{
Article \\ A Comparative Investigation of the Effect of Microstructure and Crystallographic Data on Stress-Oriented Hydrogen Induced Cracking Susceptibility of API 5L X70 Pipeline Steel
}

\author{
Mohammad Ali Mohtadi-Bonab ${ }^{1, *(\mathbb{D})}$, Edwan Anderson Ariza-Echeverri ${ }^{2,3}$ (D) and Mohammad Masoumi ${ }^{4}$ (D) \\ 1 Department of Mechanical Engineering, University of Bonab, Bonab, Iran \\ 2 Metallurgical and Materials Engineering Department, University of São Paulo, Av. Prof. Mello Moraes, \\ São Paulo 01000-000, Brazil; andersonariza@usp.br \\ 3 Escuela de Tecnología Mecánica, Universidad Tecnológica de Pereira, Carrera 27 \#10-02 Alamos, \\ Pereira 660003, Colombia \\ 4 Centro de Engenharia, Modelagem e Ciências Sociais Aplicadas, Universidade Federal do ABC, \\ Santo André 09210-580, Brazil; mohammad.m@ufabc.edu.br \\ * Correspondence: m.mohtadi@ubonab.ac.ir
}

Citation: Mohtadi-Bonab, M.A.; Ariza-Echeverri, E.A.; Masoumi, M A Comparative Investigation of the Effect of Microstructure and Crystallographic Data on Stress-Oriented Hydrogen Induced Cracking Susceptibility of API 5L X70 Pipeline Steel. Metals 2022, 12, 414. https://doi.org/10.3390/ met12030414

Academic Editors: Filippo Berto, Soran Birosca and Luis Reis

Received: 10 January 2022

Accepted: 24 February 2022

Published: 26 February 2022

Publisher's Note: MDPI stays neutral with regard to jurisdictional claims in published maps and institutional affiliations.

Copyright: (c) 2022 by the authors. Licensee MDPI, Basel, Switzerland. This article is an open access article distributed under the terms and conditions of the Creative Commons Attribution (CC BY) license (https:// creativecommons.org/licenses/by/ $4.0 /)$.

\begin{abstract}
In this research, stress-oriented hydrogen induced cracking (SOHIC) test was carried out on a $50 \mathrm{~mm}$ thickness of a commercial API 5L X70 steel plate. The evolution of microscopic features such as phase, boundary, interface, grain, and crystallographic data was analyzed before and after SOHIC, in order to comprehend the effect of crystallographic orientation on SOHIC propagation. Chemical composition and previous thermomechanical processing even finish rolling temperature and cooling rate determine the ferrite matrix microstructure. A recrystallized ultrafine ferrite grain with about 3-5\% degenerated pearlite dispersed in the microstructure was characterized, called as-received specimen. The average lattice strain and dislocation density was calculated first using multiple Gaussian peak-fitting method from XRD pattern. Electrochemically charged combination mixed $\mathrm{H}_{2} \mathrm{~S}$ $\mathrm{CO}_{2}$ solution, constant hydrogen injection, and external loading were applied to tensile specimen, in order to simulate the $\mathrm{H}_{2} \mathrm{~S}$ and $\mathrm{CO}_{2}$ environment. The results show that local misorientation and Taylor factor analyses predicted the possibility of hydrogen crack nucleation especially at boundaries and interfaces. Moreover, SOHIC crack propagation occurred along the mid-thickness of the cross section of steel plate along the ferritic boundaries, pearlitic colonies, and ferrite-cementite interfaces. Moreover, the crack propagated along distorted $\{110\}$ and $\{001\}$ grains, indicating a strong strain gradient towards the boundaries. The analysis of XRD patterns of SOHIC tested specimen by multiple Gaussian peak-fitting method estimated about $68 \%$ increment in micro-deformation and approximately $170 \%$ increase in dislocation density.
\end{abstract}

Keywords: stress-oriented hydrogen induced cracking; crystallographic orientation; pipeline steel; crack nucleation; crack propagation

\section{Introduction}

An increasing demand for natural gas and oil products makes it necessary to use steel pipelines to carry oil and gas products over long distances from their source to refineries. This requires a cost-effective transportation system traversing a harsh environment. Highpressure natural gas and oil product transmission pipelines are mostly fabricated from high strength low alloy (HSLA) steels. Such HSLA steels demonstrate promising technical and economical points. An excellent combination of strength and toughness is obtained by refining their structure, while good formability and weldability in these steels are due to the low carbon and alloying elements content [1].

The combination of microstructure and crystallographic data determines both hydrogen trapping and hydrogen diffusion through steel. Haidemenopoulos et al. [2] investigated 
the stress-oriented hydrogen-induced cracking (SOHIC) in riser steel operating under wet $\mathrm{H}_{2} \mathrm{~S}$ service conditions. They showed that the cracks initiated from the welded zone and propagated along the rolling direction in the middle of the pipe thickness. The SOHIC crack propagation occurred by cleavage mechanism and some linking cracks were found. The severe wet $\mathrm{H}_{2} \mathrm{~S}$ conditions and complex stress triaxiality affect a relatively large area of pipe thickness, indicating the nature of the SOHIC mechanism. Hydrogen trapping is determined by microstructural features (microconstituents and crystallographic data). Park et al. [3] studied the effect of three different microstructures including ferrite $(\mathrm{F})$, degenerated pearlite (DP), and bainite (B) on hydrogen-induced cracking (HIC) of a API X65 grade linepipe steel. According to their results, the hydrogen trapping efficiency is increased from DP to bainitic ferrite $(\mathrm{BF})$ and acicular ferrite (AF). Moreover, these researchers observed that HIC cracks nucleated form the local martensite/austenite $(\mathrm{M} / \mathrm{A})$ concentrated region with the steel microstructure of ferrite/acicular ferrite (F/AF) or ferrite/binite (F/B).

The accepted theory about HIC is internal pressure theory (IPT) $[4,5]$ which is based on the hydrogen pressure buildup at the microstructural defects. Hydrogen atoms are accumulated at the microstructural defects such as inclusions, precipitates and dislocations and their combination creates a high pressure-induced crack. In this regard, Mousavi Andijan et al. [6] investigated HIC susceptibility in an $\mathrm{X} 65$ pipeline steel in a $\mathrm{H}_{2} \mathrm{~S}$-containing environment. These authors suggested that hydrogen atoms are accumulated in the empty spaces between ferrite grain boundaries, pearlite layers and in the empty space between the inclusions and metal matrix. When the hydrogen atoms are combined at these locations to form hydrogen gas, a high amount of pressure is provided which is high enough to induce HIC. Diffused hydrogen atoms agglomerate in inclusions, dislocations grain boundaries, segregation zones and others.

Based on the above discussion, one can see that $\mathrm{H}$ recombination into $\mathrm{H}_{2}$ inside the microstructural defects is the main reason for HIC occurrence. It is worth mentioning that the hydrogen atoms are produced due to the corrosion reactions between the steel and hydrogen sulfide. At the surface of steel, hydrogen sulfide ions ( $\mathrm{HS}^{-}$) act as hydrogen recombination poisons and prevent hydrogen molecule formation. However, hydrogen atoms can combine together after permeating through the microstructure of steel.

Previous observations reported that a considerable amount of hydrogen usually penetrates and becomes trapped in API 5L grade steel causing hydrogen cracking at the steel cross-section, while hydrogen-permeation tests proved a slightly higher hydrogen trap density at the center of the cross-section in comparison with the surface [3,7-9]. Tensile and fatigue tests proved that the ductility dropped by $83 \%$ in acidic and harsh environments [7]. The electron backscatter diffraction (EBSD) technique revealed that HIC crack propagation is controlled by boundaries, ferrite-cementite interfaces, and crystallographic planes. The cleavage in $<001>/ / N D$-oriented grains in a ferritic structure was identified mainly along the crack path. However, a high volume fraction of grains associated with $<110>/ / N D$ and $<111>/ /$ ND-oriented grains belong to close compact planes and directions in bodycentered cube (BCC) low carbon content steels with ferrite structure show crack barrier behavior [8,10-12]. The SOHIC crack tends to propagate horizontally and the crack tip acts as very small void to which pressure-induced molecular hydrogen provides a driving force for crack propagation [13]. The cooling rate conditions can also play a significant role on crack initiation and propagation due to the tailoring of phase transformation. For instance, the martensite phase is considered as the weakest microstructure against hydrogen embrittlement [14].

This paper aimed to quantify the combined effect of hydrogen charging and uniaxial tensile loading on crack propagation in an API 5L X70 pipeline steel. Therefore, microstructural features involving the phases and crystallographic data were analyzed using the X-ray diffraction (XRD), scanning electron microscopy (SEM), and electron backstroked diffraction (EBSD) techniques to evaluate and quantify the crystallographic atomic changes after the SOHIC test. SOHIC crack propagation was crystallographically studied to comprehend 
the role of grain orientations, boundaries, interfaces, and kernel average misorientation to predict the mechanical response against external loading by the Taylor method.

\section{Materials and Methods}

A commercial plate of API grade 5L X70 (Fe-0.09C-1.56Mn-0.35Si-0.002S-0.002P-0.02Cr$0.11 \mathrm{Ni}(\mathrm{wt} \%)$ ) with a thickness of $50 \mathrm{~mm}$ was used is this study. The chemical composition was determined using an optical emission spectrometer with spark discharge. In order to reveal the microstructure, the middle of the rolling direction plane of the pipeline specimen was ground and polished with $1 \mu \mathrm{m}$ diamond paste suspension at the final step of polishing and then etched with $2 \%$ nital solution for $15 \pm 5 \mathrm{~s}$. A Quanta FEG 450 scanning electron microscope (FEI, Hillsboro, OR, USA) was used to investigate the microstructure features, before and after the SOHIC test. Also, a microhardness test was performed according to the ASTM E-384 standard along the mid-thickness of specimens with $4.903 \mathrm{~N}$ indentation load for $15 \mathrm{~s}$ (HV0.5) and 15 repetitions.

Stress-oriented HIC, like HIC, occurs due to hydrogen embrittlement associated with hydrogen trapping along the rolling/drawing direction. Electrochemical hydrogen charging was utilized to investigate the role of hydrogen embrittlement on tensile properties. Five tensile specimens from API 5L X70 steel were prepared using an EDM wire cutting machine. Then, the tensile specimens were electrochemically charged by using $2 \mathrm{~L}$ of mixed solution of $0.2 \mathrm{M} \mathrm{H}_{2} \mathrm{SO}_{4}$ and $3 \mathrm{~g} / \mathrm{L} \mathrm{NH}_{4} \mathrm{SCN}$ using a DC current power supply for $24 \mathrm{~h}$ with hydrogen at a constant current density of $20 \mathrm{~mA} / \mathrm{cm}^{2}$. Notably, the mentioned hydrogen charging test models a more severe environment than the $\mathrm{H}_{2} \mathrm{~S}_{-} \mathrm{CO}_{2}$ gas, because the experiment injects much more hydrogen atoms inside the steel specimens coupled with external loading about $20 \mathrm{~N}$ [11]. To determine the effect of SOHIC test, the microstructure and crystallographic data was measured by EBSD. A cross section of SOHIC- tested specimen was ground and polished to $1 \mu \mathrm{m}$, then automatically polished by vibrometery polishing using $0.05 \mu \mathrm{m}$ colloidal silica slurry for $2 \mathrm{~h}$. EBSD was conducted using a FEI Quanta FEG 450 scanning electron microscope operating at an acceleration voltage of $20 \mathrm{kV}$, specimen tilt angle of $70^{\circ}$, working distance of $12 \mathrm{~mm}$ and $0.5 \mu \mathrm{m}$ step size. The Channel 5 software and MTEX were used to analyze and display the data.

X-ray diffraction (XRD) was measured with Cu-Ka radiation (45 kV and $40 \mathrm{~mA}$ ) in a diffractometer at continuous scanning mode at $2 \mathrm{Q}$ between $40^{\circ}$ and $105^{\circ}$ and with a step of $0.005^{\circ}$ for $1 \mathrm{~s}$. pattern using Debye-Scherer's relation combined with the Stoke Wilson formula. The dislocation density $(\delta)$ was evaluated using Equation $(1)[15,16]$ :

$$
\delta=\frac{1}{D^{2}}
$$

where $D$ is the grain size associated with relationship between grain size and peak broadening as Debye-Scherer's relation shown in Equation (2):

$$
D=\frac{k \lambda}{\beta \cos \theta}
$$

where $k$ is the shape factor with the amount of $0.9, \lambda$ is ray wavelength, $\beta$ is the full width at half maximum (FWHM), and $\theta$ is the X-ray diffraction angle in degree. The micro-strain was calculated using the Stoke Wilson formula shown in Equation (3):

$$
\varepsilon=\frac{\beta}{4 \tan \theta}
$$

Macrotexture measurements were also carried out in mid-thickness along the rolling direction, using an X'Pert Pro diffractometer (PanAlytical, Malvern, UK) equipped with a $\mathrm{Cu}$ radiation source and texture goniometer. Three incomplete $\{110\},\{200\}$ and $\{211\}$ pole figures were obtained in the reflection mode on a $5^{\circ}$ grid up to $85^{\circ}$ specimen tilt. 
The orientation distribution function (ODF) of specimens was then calculated from the measured pole figures using the ATEX free and open-source software toolbox [17].

A new multiple Gaussian peak-fitting method was proposed in this paper to extract the real crystal profile from the total overlaps experimental profile. The best polynomials fitting was estimated by five sub-peaks to calculate the origin of peak broadening from the real crystal configuration. Novikov et al. [18] reported that the broadening the diffraction peaks is governed by linear crystalline defects, since microscopic stresses (e.g., boundaries and interfaces) were neglected. Heterogeneous peak broadening of the experimental diffraction results could be affected by localized lattice distortion and micro-segregation elements. Therefore, deconvolution of experimental broadening could modify Gaussian profile, resulting in better approximation. Although theoretical analysis of the width of the diffraction peak is explained by a Gaussian function that fits the experimental data well, some valuable information about the structure and short-range disturbance of lattice were neglected. Klug et al. [19] reported poor linear Bragg's equation by assuming Gaussian broadening functions for both strain and size due to the localized micro-strain effect and local fluctuations in the concentrations of the alloying elements. Bagherian et al. [20] was employed a differential weight nonuniform lattice strain to describe the nonuniform peak broadening as:

$$
\sum_{i=1}^{n}\left(d_{h k l} \cdot \beta_{h k l} \cos \theta_{i}\right)^{2}=\frac{3}{4 D}\left(d_{h k l}^{2} \cdot \beta_{h k l} \cos \theta\right)+\left(\frac{\varepsilon_{i}}{2}\right)
$$

where $\varepsilon_{i}$ represents each sub-peak of experimental diffraction profile. Garcia et al. [21] investigated the distribution of alloying element concentration in low carbon API X70 steel by the atom probe tomography (APT) technique. They showed carbon interfacial segregation at crystallographic defects (i.e., boundaries, dislocations, and at precipitates) in atomic-scale resolution (less than $20 \mathrm{~nm}$ ). Therefore, strain-induced associated with crystal defects and lattice distortion leads to a non-uniform Gaussian distribution function. The experimental (110) peak was composed into five sub-peaks to better estimate the peak position, integrated intensity, and peak broadening, and the dislocation density and micro-strain due to the low spectral resolution of the spectrometer. Imperfection in crystal and atomic configuration has a vital effect on the lattice misfits. The dislocationinduced structure obtains positive and negative lattice misfits during production, and the service periods are characterized by five subpeaks separate and broadened, indicating the difference between the BCC lattice parameters, defects, or a charged interface induced through strain relaxation at the ferrite-carbides interfaces.

\section{Results and Discussion}

Figure 1a,b show the SEM microstructure of as-received API 5L steel in two different regions containing the polygonal/semi-polygonal ferrite with a small fraction of degenerated pearlite, mainly at the boundaries, which commonly develops during hot-rolling of low carbon-low alloy steels. Degenerated pearlite is considered as non-lamellar pearlite due to the lack of carbon and micro-segregation element alloys in hypo-eutectoid steels [22]. The presence of a small fraction of pearlite could be explained by the interdendritic microsegregation, such as manganese in the prior austenite grains. The fine ferritic structure of about $5.5 \pm 0.5 \mu \mathrm{m}$ was exhibited in the investigated steel due to the presence of microalloying elements such as $\mathrm{Ti}$, followed the thermomechanical processing [23]. The role of grain size on hardness and mechanical properties is well-understood by the Hall-Petch equation. Grain boundaries and ferrite-cementite interface act as barriers against dislocation gliding, thereby increase the resolved shear stress of plastic deformation. Hardness value was estimated with the approximate amount of $354 \pm 14$ HV0.5 in this steel.

Notably, the tiny proportion of degenerated pearlite and the absence of acicular ferrite could result in better mechanical and corrosion behavior in X70 steel [24]. Moreover, the presence and distribution of inclusions (such as $\mathrm{MnS}$ and oxide-type) were negligible in the investigated steel. 
(a)

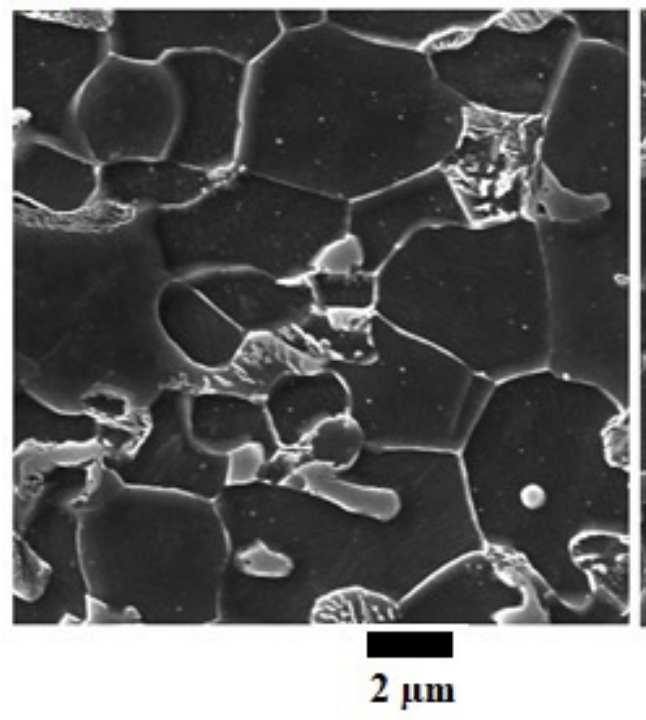

(b)

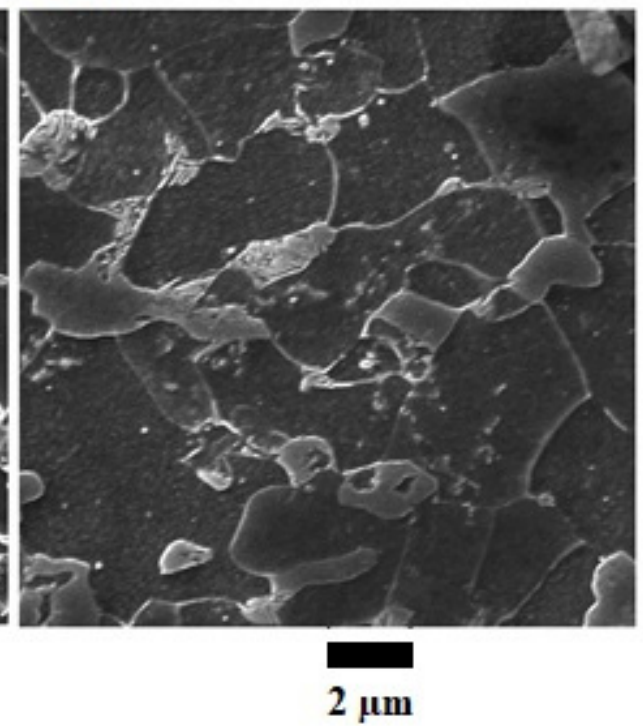

Figure 1. (a,b) SEM microstructure at the surface of as-received API 5L X70 steel.

The XRD patterns of the investigated specimen are shown in Figure 2. The XRD spectrum shows the presence of a fully body-centered cube (BCC) ferritic structure with no carbide content due to the accuracy of the experimental conventional XRD diffraction methods. Luo et al. [25] introduced multiple Gaussian peak-fitting methods to calculate the atomic configuration in medium carbon steel. The (110) $\alpha$ spectrum peak with the highest penetration level was separated into five overlapping diffraction peaks using the self-made numerical process of Gaussian multiple peaks to estimate the peak position, integrated intensity, and peak broadening (full-width at half-maximum). These distinct five sub-peaks (adj $\left.\mathrm{R}^{2}=0.999886\right)$ variations are listed in Table 1 to calculate dislocation density due to the carbon segregation to dislocations during thermomechanical processing and the effect of microsegregation and precipitation at the ferritic matrix. Carbon and alloying element segregation increased the dislocation density to develop cellular dislocation structure, which gradually increased by increasing the level of straining during thermomechanical processing. Such gradual increase of dislocation density can be detected by peak broadening analysis suggested by the Debye-Scherrer method [26]. XRD analyses combined with multiple Gaussian peak-fitting methods estimated the average lattice strain and dislocation density was $1.068 \times 10^{-3}$ and $2.90 \times 10^{13} \mathrm{~m}^{-2}$, respectively. Such a low dislocation density could be related to the full or partial dynamic recrystallization and recovery during thermomechanical processing.

Table 1. Peak parameters such as crystallite size $(D)$, dislocation density $(\delta)$, micro-strain $(\varepsilon)$ for five sub-peaks using the self-made numerical process of Gaussian multiple of as-received specimen.

\begin{tabular}{cccccc}
\hline $\begin{array}{c}\text { Diffraction Peak } \\
\text { (Normalized) }\end{array}$ & Angle (2Theta) $\left.\mathbf{(}^{\circ}\right)$ & $\begin{array}{c}\text { Full Width at Half Maximum } \\
\text { (FWHM) }\end{array}$ & $\begin{array}{c}\text { Interplanar } \\
\text { Spacing }(\boldsymbol{D})(\mathbf{n m})\end{array}$ & $\begin{array}{c}\text { Dislocation Density } \\
\left(\boldsymbol{\delta} \times \mathbf{1 0}^{\mathbf{1 4}}\right)\left(\mathbf{m}^{-\mathbf{2}}\right)\end{array}$ & $\begin{array}{c}\text { Average Lattice } \\
\text { Strain }\left(\boldsymbol{\varepsilon} \times \mathbf{1 0}^{-\mathbf{3}}\right)\end{array}$ \\
\hline Peak 1 & 44.471 & 0.133 & 55.339 & 0.327 & 1.418 \\
Peak 2 & 44.555 & 0.036 & 201.825 & 0.025 & 0.388 \\
Peak 3 & 44.504 & 0.229 & 32.064 & 0.973 & 0.011 \\
Peak 4 & 44.696 & 0.024 & 303.502 & 0.115 & 0.257 \\
Peak 5 & 44.779 & 0.079 & 93.097 & $0.2900 \pm 0.0005$ & $1.0684 \pm 0.001$ \\
& & & &
\end{tabular}




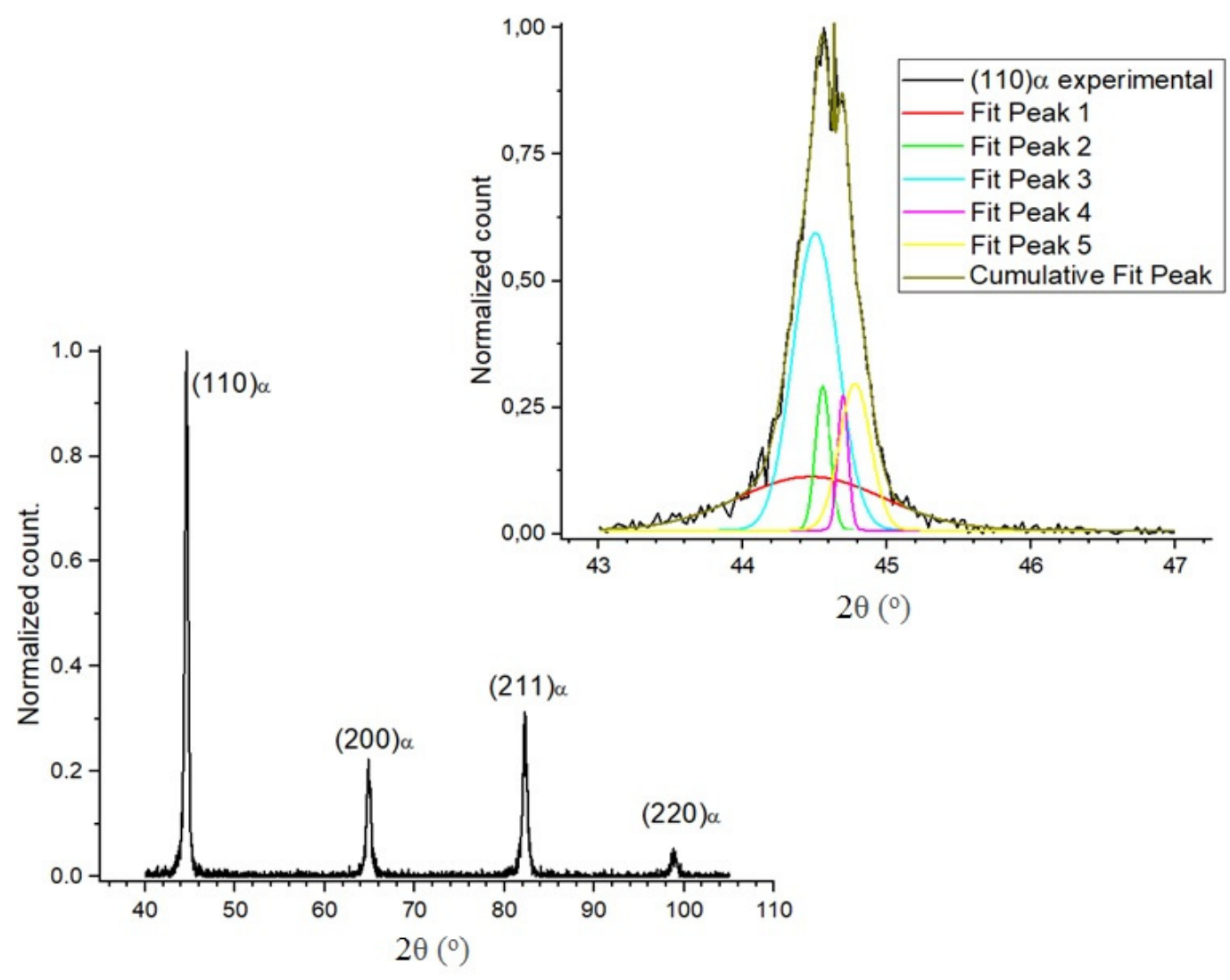

Figure 2. XRD patterns of the investigated specimen.

The crystallographic texture evolution during thermomechanical control processing and further subsequent treatment were investigated to predict the effect of texture distribution on further deformation mechanisms. Figure 3 presents the ODF at constant $\phi 2=45^{\circ}$, representing the known material's crystallographic texture in steel. The dominant $\{001\}$ and $\{111\}$ fiber planes parallel to the rolling plane (RD) were characterized in the specimen. It is known that $\{001\}$ planes in BCC structure have the least atomic packing factors, making the slide in these planes almost impossible. Thereby, dislocation accumulation and micro-strain gradient would develop at boundaries associated with $\{001\}$ grains. On the other hand, slip occurs in compact $<111>$ direction in BCC structure along activated $\{110\},\{112\},\{123\}$ planes due to the resolved shear stress explained by Schmid factor. Therefore, a complex plastic response is expected in this fine ferritic steel. The ODF shows that (001) $[1 \overline{2} 0],(001)[1 \overline{1} 0]$ and (001) [230] crystallographic orientations were predominant in the $(001) / / R D$, while $(111)[0 \overline{1} 1],(111)[1 \overline{2} 1]$, and (111) [123] were dominant among (111)/ / RD crystallographic orientations.

Yang et al. [27] studied the effect of shear deformation during hot rolling in a Fe$0.01 \mathrm{C}-2.8 \mathrm{Si}-0.8 \mathrm{Al}(\mathrm{wt} \%)$ steel and reported that initial $\{100\}$ textures could be related to the columnar grains during the solidification, in which, for example the $\{001\}<120>$ orientation can rotate around the $<100>$ axis parallel the rolling plane to the Brass type orientation $\{110\}<112>$ under shear deformation. On the other hand, Xie et al. [28] reported that the formation of a strong $\{001\}$ texture components could be associated with recrystallization annealing of rolled low alloy carbon steel. Therefore, strong cube and Goss recrystallization textures could be formed at grain boundaries between $\{001\}$ and $\{111\}$ grains due to the specifically oriented nucleation and oriented growth due to the grain boundary mobility in the BCC structure [29].

Figure $4 \mathrm{a}$ shows the normal direction orientation image mapping showing the crystallographic orientation of each grain with point-to-point misorientation greater than $15^{\circ}$. Hence, a random orientation texture is identified in this region and a slight fraction of (110) 
and (112) grains parallel to the rolling plane is shown in this figure. It is clear that (110) and (112) planes are considered as the principal close-packed planes in BCC structure and are activated at higher temperatures during thermomechanical processing. A low fraction of medium-angle boundaries $\left(5^{\circ}<\theta<15^{\circ}\right)$ also proves that dynamic recrystallization would effectively occur, resulting in a low distorted structure. As shown in Figure 4b, Kernel average misorientation (KAM) analysis shows the local plastic strain due to the localized crystallographic orientation distortion. Grain boundaries associated with (110) and (111) planes revealed the highest lattice distortion, rarely exceeding $3.0^{\circ}$. Such lattice distortion and crystallographic defects could generate and accumulate stored energy to nucleate micro-cracks or provide adequate resolved shear to pass dislocation into the neighboring grain. Taylor model based on three different slip systems (i.e., $\{110\}<111>,\{112\}<111>$, and $\{123\}<111>$ ) was simulated according to the uniaxial tension loading matrix to predict the behavior of each grain. At least five independent activated slip systems are required for commencing the plastic deformation. Soft grains with blue color in Figure 4c indicate that these grains already provide sufficient slip systems, while hard grains with red color are restricted to any further rotation for further necessary slip systems. Therefore, the nucleation of micro-cracks is probable in these boundaries and these micro-cracks can propagate in intergranular or transgranular manner due to the lattice distortion and stored energy of the individual grains.

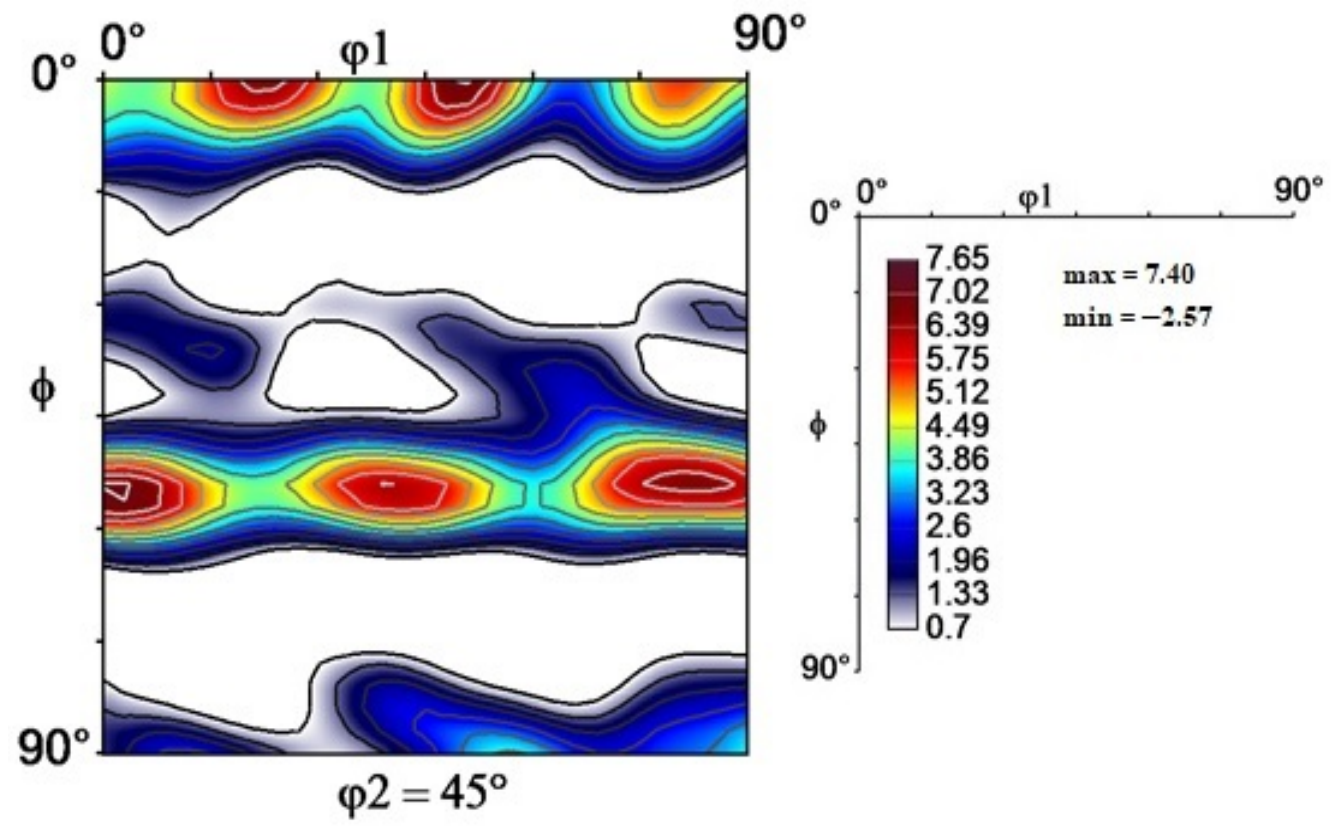

Figure 3. ODF at constant $\phi 2=45^{\circ}$ of as-received specimen.

The role of crystallographic data on stress-oriented hydrogen-induced cracking (SOHIC) was investigated on the SOHIC-cracked specimen using EBSD technique. Orientation Imaging Microscopy (OIM), Kernel Average Misorientation (KAM), and Taylor factor maps and their levels were calculated and represented in Figure 5. The highest local misorientation level at grain boundaries is evidence of the highest concentration of hydrogen. Ferritic matrix microstructures with a micro-scaled amount of High Angle Grain Boundaries (HABs) are prone to HIC cracking. Both intergranular and transgranular crack propagation are found along the horizontal crack path. A high grain deformation gradient is observed in the neighboring grains of the crack path. Cracks predominantly propagate along with the HABs while it propagates in transgranular manner within the (001) grains. Nanostructured grain sizes are required to stop crack propagation. The grain refining alloying elements such as $\mathrm{V}$ and $\mathrm{Nb}$ are suggested for the next generation of pipeline steels in harsh environments. A larger fraction of random grain boundaries can trap more hydrogen at nodes or triple junctions decreasing the permeability. According to the Hall-Petch equation, 
the increase of the number of grain boundaries increases the mechanical response level against the external loading. Thus, cracks propagate more readily in a material with larger grain size. The SOHIC cracks propagated along (110) and (001) grains. Notably, the cracks propagated in transgranular manner through (001) grains.

(b)

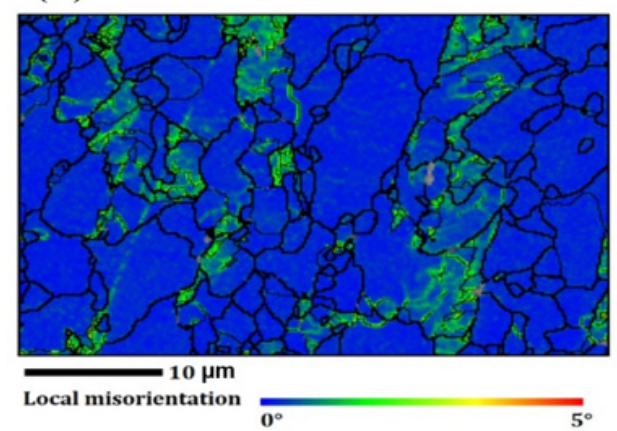

(a)

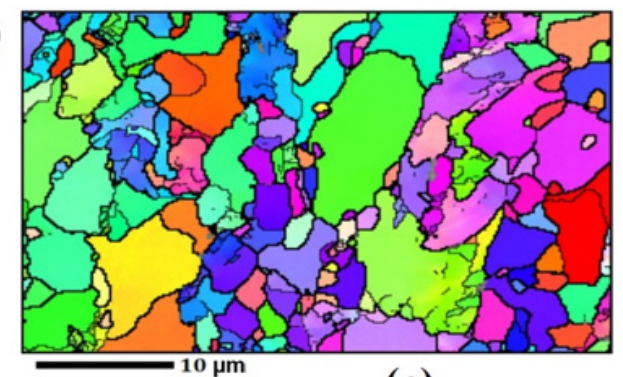

(c)
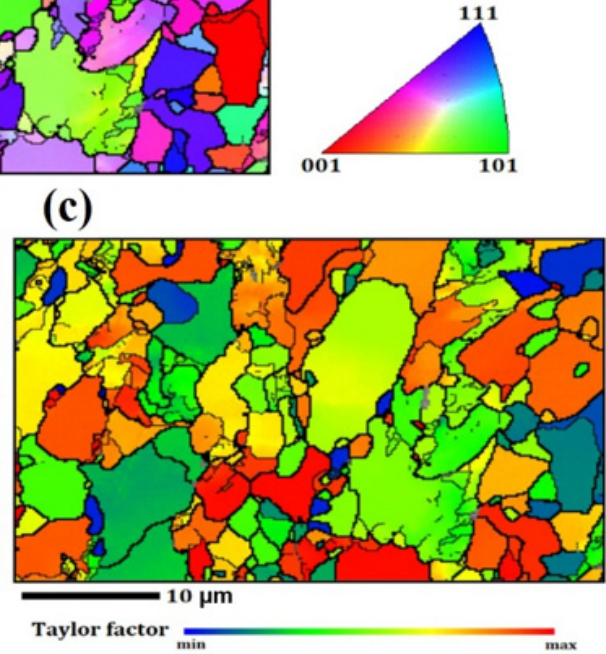

Figure 4. (a) Normal direction orientation image, (b) Kernel average misorientation, and (c) Taylor factor maps of the as-received API X70 steel.

Grain orientation and grain boundaries effectively impact plastic deformation and fracture toughness. High angle boundaries with high crystallographic misfits provide a low-energy path for facilitating crack propagation, whereas a crack may propagate along LABs inside the grain rather than through the grain boundary [12]. In other words, LABs can facilitate newly formed crack branching. Moreover, an inhomogeneous crystallographic defects accumulation was created by SOHIC crack propagation. Crystallographic defects such as dislocation and boundaries trap hydrogen atoms, then molecular hydrogen with a bigger size distorts the crystallographic structure, increasing the hydrogen embrittlement susceptibility. Dislocation accumulation at boundaries also encourages crack propagation; therefore, the region with high KAM values with a higher dislocation density is prone to hydrogen embrittlement. Taylor factor map was used to predict the grain response against uniaxial external loading. A high Taylor factor data observed in the cracked specimen is a sign of high shear stress on slip bands. This results in a highly discorded microstructure. Consequently, the crack can freely propagate along with these grains and boundaries. The high value of Taylor factor data in all grain orientations shows that grain is crushed during SOHIC test.

It is well-known that hydrogen embrittlement susceptibility is controlled by microstructural constituents and precipitation as well as crystallographic defects (such as precipitates, inclusions, boundaries, interfaces and dislocations) [30,31]. These factors determine the hydrogen trap, mobility and even its permeability in the lattice structure. The effect of SOHIC on ferritic structure and crystallographic defects was studied using the self-made numerical process of Gaussian multiple peaks to estimate the variation of micro-deformation and dislocation density in the cracked specimen. Its XRD patterns and detail analyses of five overlapping diffraction peaks were shown in Figure 6, and related data is listed in Table 2. Results demonstrated about 68\% increment in micro-deformation and approximately $170 \%$ increase in dislocation density on the specimen subjected to the SOHIC test. Penetration of hydrogen atoms inside the steel structure, their trapping at 
crystal defects, and their recombination to form molecular hydrogen generates localized stress/strain concentrations at boundaries and interfaces. The hydrogen-induced crack was aligned through the direction of applied stress coupled with hydrogen embitterment is classified as SOHIC. The formation of hydrogen gas increases the dislocation density and micro-deformation of the recrystallized ferrite microstructure. The results show that the crack propagation mainly depends on the loading direction. In other words, the crack propagates in a direction which is almost perpendicular to the loading direction. The microscopy analyzes revealed that a combination of intergranular and transgranular crack propagation combined with $\mathrm{H}_{2}$ molecular diffusion reduced the fracture toughness of the investigated X70 steel subjected to sour service in $\mathrm{H}_{2} \mathrm{~S}$-containing environments.

(a)
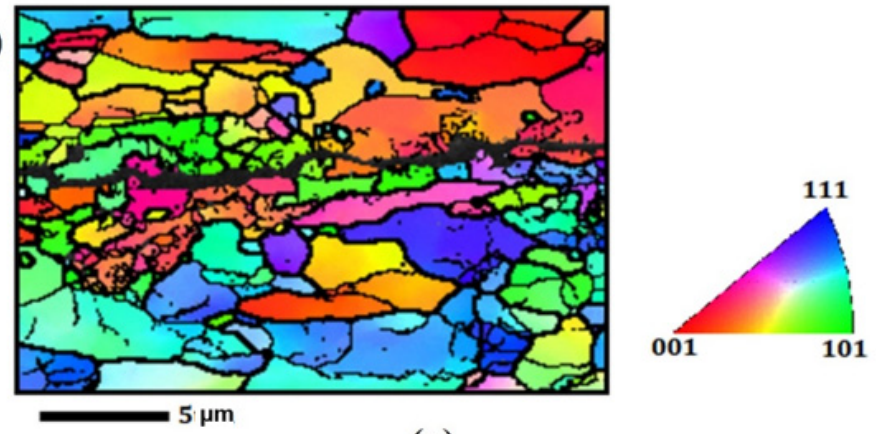

(b)

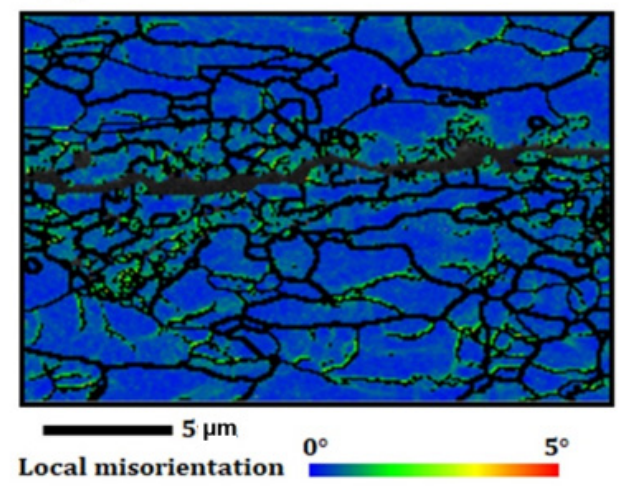

(c)

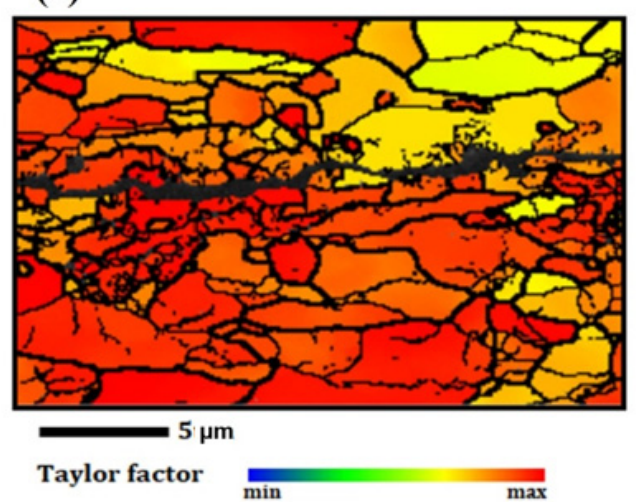

Figure 5. (a) Normal direction orientation image, (b) Kernel average misorientation, and (c) Taylor factor maps of the SOHIC tested specimen.

Table 2. Peak parameters such as crystallite size $(D)$, dislocation density $(\delta)$, micro-strain $(\varepsilon)$ for five sub-peaks using the self-made numerical process of Gaussian multiple of the SOHIC tested specimen.

\begin{tabular}{cccccc}
\hline $\begin{array}{c}\text { Diffraction Peak } \\
\text { (Normalized) }\end{array}$ & Angle (2Theta) $\left(^{\circ}\right)$ & $\begin{array}{c}\text { Full Width at Half Maximum } \\
(\text { FWHM) }\end{array}$ & $\begin{array}{c}\text { Interplanar } \\
\text { Spacing }(\boldsymbol{D})(\mathbf{n m})\end{array}$ & $\begin{array}{c}\text { Dislocation Density } \\
\left(\boldsymbol{\delta} \times \mathbf{1 0}^{\mathbf{1 4}}\right)\left(\mathbf{m}^{-\mathbf{2}}\right)\end{array}$ & $\begin{array}{c}\text { Average Lattice } \\
\text { Strain }\left(\boldsymbol{\varepsilon} \times \mathbf{1 0}^{-\mathbf{3}}\right)\end{array}$ \\
\hline Peak 1 & 45.0785 & 0.0895 & 81.951 & 0.149 & \\
Peak 2 & 44.5599 & 0.3973 & 18.496 & 2.923 & 0.941 \\
Peak 3 & 44.5174 & 0.0984 & 74.689 & 0.179 & 4.231 \\
Peak 4 & 44.1376 & 0.1742 & 42.247 & 0.560 & 1.049 \\
Peak 5 & 44.1039 & 0.0817 & 90.089 & 0.123 & 0.875 \\
& & & & $0.7870 \pm 0.0005$ & $1.7952 \pm 0.001$ \\
\hline
\end{tabular}




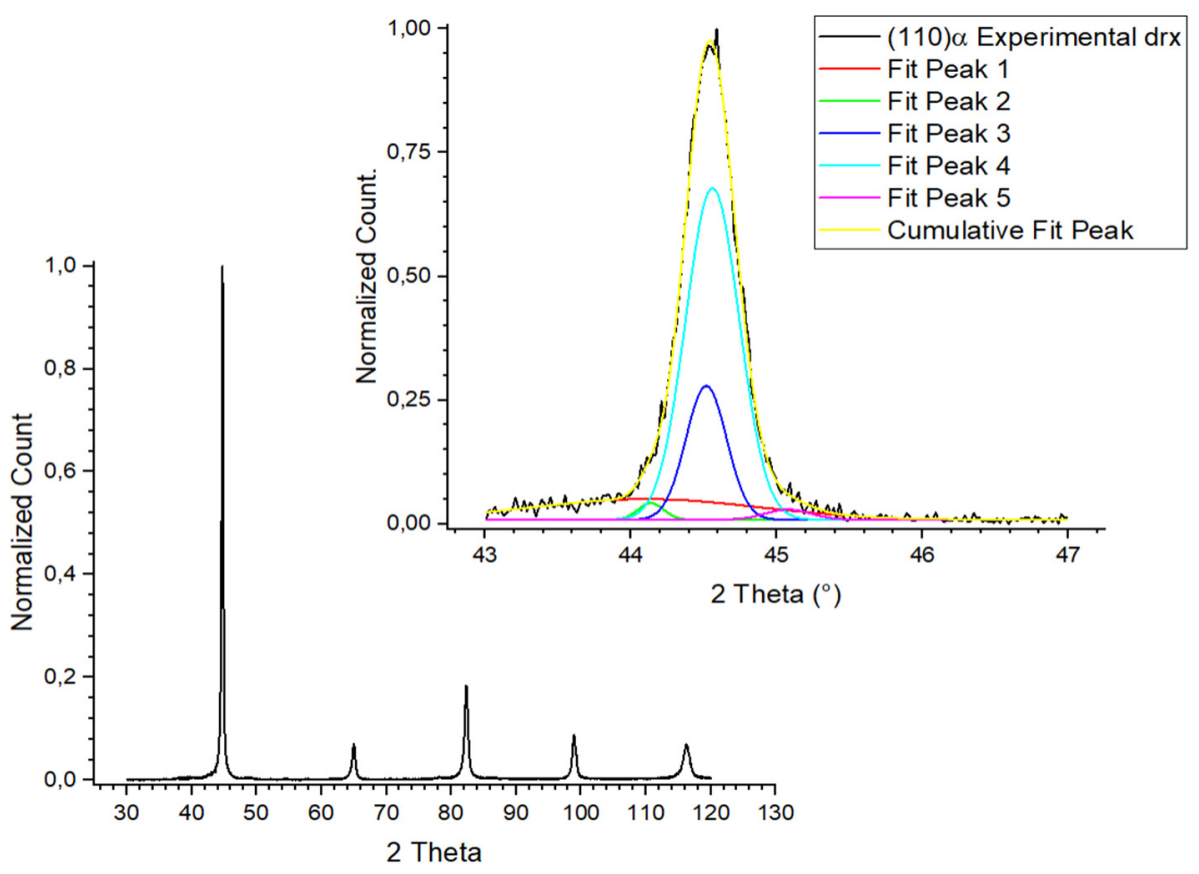

Figure 6. XRD patterns of the SOHIC tested specimen.

The variation of point-to-point misorientation and Kernel average misorientation after the SOHIC test were presented in Figure 7. A significant increase in lattice distortion within the grain is observed due to the hydrogen trapping and generation of internal stress/strain inside the grain. Strain-free recrystallized grains are introduced with very low lattice distortion. Lattice misorientation in these grains is less than $0.5^{\circ}$ among third neighboring pixel, while medium $\left(0.5^{\circ}<\mathrm{KAM}<3.0^{\circ}\right)$ and high $\left(3.0^{\circ}<\mathrm{KAM}<5.0^{\circ}\right)$ are corresponding to the restructured and deformed grains with a higher amount of stored energy. The high KAM values could be evidence of stress triaxiality, which promotes cleavage fractures. The combination of stress/strain concentration at ferrite boundaries and ferrite-cementite interfaces and residual stress first nucleates the micro-cracks and the complex stress distribution within the pipeline accelerates the SOHIC crack propagation rate. It is worth mentioning that SOHIC cracks propagate in both transgranular and intergranular manner.

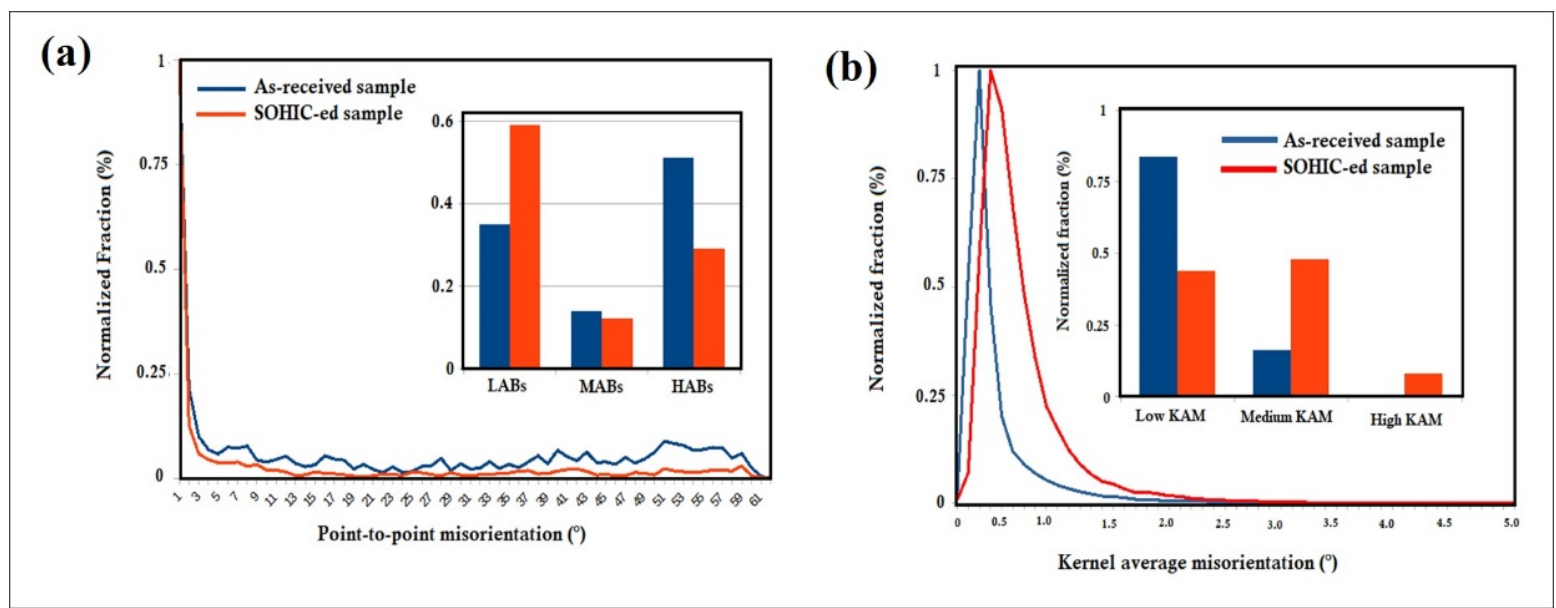

Figure 7. Comparison of (a) point-to-point misorientation and (b) Kernel average misorientation data of the EBSD data before and after the SOHIC test. 
Figure 8a,b show SEM images of two SOHIC cracks with two different magnifications observed at the mid-thickness of the cross section appeared after electrochemical hydrogen charging. Such cracks nucleated from the non-metallic inclusions due to the hydrogen buildup pressure and propagated through the hard phases or grain boundaries [32-34]. Moreover, when the crack is formed, hydrogen atoms are accumulated in the crack tip and crack tip acts as a void. Hydrogen buildup pressure at the crack tip is considered a driving force for the crack propagation.

(a)

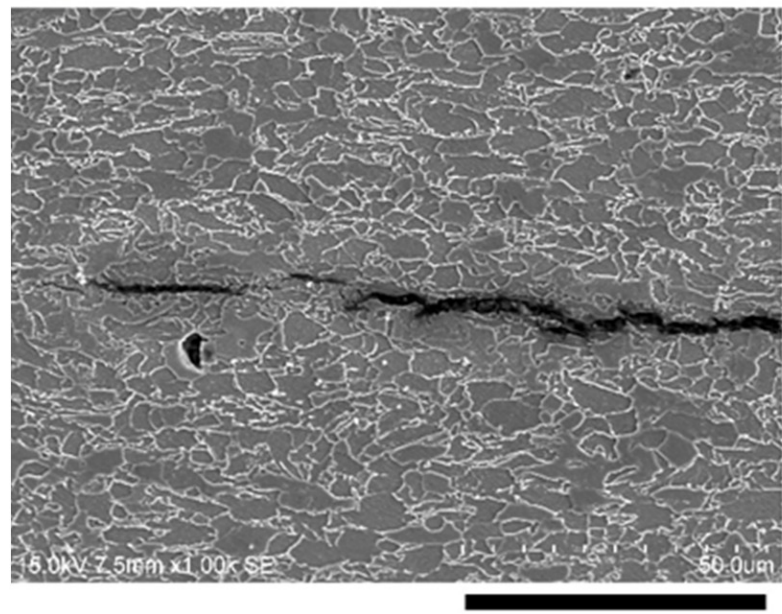

$50 \mu \mathrm{m}$ (b)

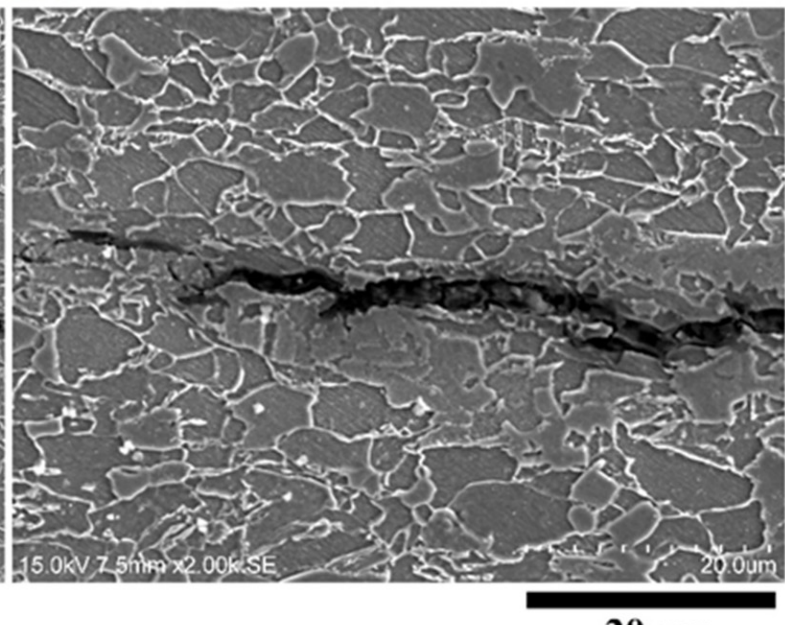

$20 \mu \mathrm{m}$

Figure 8. (a) SOHIC crack and (b) the same SOHIC crack with a higher magnification.

\section{Conclusions}

Based on the experiments and the above discussion, the following points are concluded:

(1) Dislocation accumulation and micro-strain gradient is developed at boundaries associated with $\{001\}$ grains.

(2) Local misorientation and Taylor factor analyses calculated from crystallographic data predicted the possibility of hydrogen crack nucleation especially at boundaries and interfaces.

(3) A SOHIC crack propagates along the middle of steel plate along the ferritic boundaries, pearlitic colonies, and ferrite-cementite interfaces. Moreover, the crack propagation occurs along distorted $\{110\}$ and $\{001\}$ grains indicating a strong strain gradient towards the boundaries.

(4) The analysis of XRD patterns of SOHIC-tested specimens by the multiple Gaussian peak-fitting method estimated about $68 \%$ increment in microdeformation and an approximately $170 \%$ increase in dislocation density. This indicates a high amount of hydrogen penetration of hydrogen atoms and generates excessive lattice distortion.

(5) It is expected that the excess of crystallographic defects dispersed through microstructure improve the hydrogen corrosion resistance towards both hydrogen trapping and hydrogen diffusion.

Author Contributions: M.A.M.-B.: Investigation, Methodology, Data curation, Formal analysis, Writing-review \& editing, Supervision. E.A.A.-E.: Investigation, Methodology, Data curation, Writing—review \& editing. M.M.: Conceptualization, Investigation, Methodology, Data curation, Formal analysis, Writing-original draft, Writing-review \& editing, Supervision. All authors have read and agreed to the published version of the manuscript.

Funding: This research was funded by National Council for Scientific and Technological Development (CNPq, No. 304157/2020-1) and São Paulo Research Foundation (FAPESP, No. 2021/02926-4) and Key Program of the Brazil Academy of Sciences. 


\section{Data Availability Statement: Not applicable.}

Acknowledgments: The authors acknowledge the support given by National Council for Scientific and Technological Development and São Paulo Research Foundation and Key Program of the Brazil Academy of Sciences.

Conflicts of Interest: The authors declare that they have no known competing financial interests or personal relationships that could have appeared to influence the work reported in this paper.

\section{References}

1. Weglowski, M.S.; Dymek, S.; Kopyściański, M.; Niagaj, J.; Rykała, J.; de Waele, W.; Hertelé, S. A comprehensive study on the microstructure and mechanical properties of arc girth welded joints of spiral welded high strength API X70 steel pipe. Arch. Civ. Mech. Eng. 2020, 20, 14. [CrossRef]

2. Haidemenopoulos, G.N.; Kamoutsi, H.; Polychronopoulou, K.; Papageorgiou, P.; Altanis, I.; Dimitriadis, P.; Stiakakis, M. Investigation of Stress-Oriented Hydrogen-Induced Cracking (SOHIC) in an Amine Absorber Column of an Oil Refinery. Metals 2018, 8, 663. [CrossRef]

3. Park, G.T.; Koh, S.U.; Jung, H.G.; Kim, K.Y. Effect of microstructure on the hydrogen trapping efficiency and hydrogen in-duced cracking of linepipe steel. Corros. Sci. 2008, 50, 1865-1871. [CrossRef]

4. Zapffe, C.; Sims, C. Hydrogen embrittlement, internal stress and defects in steel. Trans. AIME 1941, $1037,1-37$.

5. Tetelman, A.S. Fundamental Aspects of Stress Corrosion Cracking; National Association of Corrosion Engineers: Houston, TX, USA, 1969; pp. 446-460.

6. Anijdan, S.M.; Arab, G.; Sabzi, M.; Sadeghi, M.; Eivani, A.; Jafarian, H. Sensitivity to hydrogen induced cracking, and corro-sion performance of an API X65 pipeline steel in $\mathrm{H}_{2} \mathrm{~S}$ containing environment: Influence of heat treatment and its subse-quent microstructural changes. J. Mater. Res. Technol. 2021, 15, 1-16. [CrossRef]

7. Mohtadi-Bonab, M.A.; Eskandari, M.; Rahman, K.; Ouellet, R.; Szpunar, J. An extensive study of hydrogen-induced cracking susceptibility in an API X60 sour service pipeline steel. Int. J. Hydrogen Energy 2016, 41, 4185-4197. [CrossRef]

8. Masoumi, M.; Silva, C.C.; Béreš, M.; Ladino, D.H.; de Abreu, H.F.G. Role of crystallographic texture on the improvement of hydrogen-induced crack resistance in API 5L X70 pipeline steel. Int. J. Hydrogen Energy 2017, 42, 1318-1326. [CrossRef]

9. Mohtadi-Bonab, M.A.; Szpunar, J.; Razavi-Tousi, S.S. A comparative study of hydrogen induced cracking behavior in API 5L X60 and X70 pipeline steels. Eng. Fail. Anal. 2013, 33, 163-175. [CrossRef]

10. Masoumi, M.; Silva, C.C.; de Abreu, H.F.G. Effect of crystallographic orientations on the hydrogen-induced cracking re-sistance improvement of API 5L X70 pipeline steel under various thermomechanical processing. Corros. Sci. 2016, 111, 121-131. [CrossRef]

11. Mohtadi-Bonab, M.A.; Masoumi, M.; Szpunar, J. A comparative fracture analysis on as-received and electrochemically hydro-gen charged API X60 and API X60SS pipeline steels subjected to tensile testing. Eng. Fail. Anal. 2021, 129, 105721. [CrossRef]

12. Ramirez, M.F.; Hernández, J.W.; Ladino, D.H.; Masoumi, M.; Goldenstein, H. Effects of different cooling rates on the microstructure, crystallographic features, and hydrogen induced cracking of API X80 pipeline steel. J. Mater. Res. Technol. 2021, 14, 1848-1861. [CrossRef]

13. Mohtadi-Bonab, M.A.; Mousavi, H.; Pourazizi, R.; Szpunar, J. Finite element modeling of HIC propagation in pipeline steel with regard to experimental observations. Int. J. Hydrogen Energy 2020, 45, 23122-23133. [CrossRef]

14. Pourazizi, R.; Mohtadi-Bonab, M.A.; Szpunar, J. Role of texture and inclusions on the failure of an API X70 pipeline steel at different service environments. Mater. Charact. 2020, 164, 110330. [CrossRef]

15. Kuznetsov, A.Y.; Machado, R.; Gomes, L.S.; Achete, C.A.; Swamy, V.; Mud-dle, B.C.; Prakapenka, V. Size dependence of ru-tile TiO2latticeparameters determined via simultaneous size, strain, and shape modeling. Appl. Phys. Lett. 2009, 94, 193117. [CrossRef]

16. Wilson, G.J.; Matijasevich, A.S.; Mitchell, D.R.G.; Schulz, J.C.; Will, G.D. Modification of TiO2 for Enhanced Surface Proper-ties: Finite Ostwald Ripening by a Microwave Hydrothermal Process. Langmuir 2006, 22, 2016-2027. [CrossRef]

17. Ernould, C.; Beausir, B.; Fundenberger, J.-J.; Taupin, V.; Bouzy, E. Integrated correction of optical distortions for global HR-EBSD techniques. Ultramicroscopy 2020, 221, 113158. [CrossRef]

18. Novikov, D.V.; Ohler, M.; Köhler, R.; Materlik, G. Observation of defects in crystal surface layers by grazing-incidence dif-fraction X-ray topography. J. Phys. D Appl. Phys. 1995, 28, A84-A87. [CrossRef]

19. Klug, H.P.; Alexander, L.E. X-ray Diffraction Procedures, 2nd ed.; John Wiley and Sons: New York, NY, USA, 1974.

20. Bagherian, S.; Zak, A.K. X-ray peak broadening and optical properties analysis of $\mathrm{SnO} 2$ nanosheets prepared by sol-gel method. Mater. Sci. Semicond. Process. 2016, 56, 52-58. [CrossRef]

21. Garcia, M.P.; Chen, H.; Eizadjou, M.; Lim, B.; Ringer, S.P.; Barbaro, F.J. Quantitative analysis of Nb in solid solution in low carbon steels by atom probe tomography and inductively coupled plasma mass spectroscopy. Mater. Charact. 2021, 179, 111308. [CrossRef]

22. Xu, P.; Liang, Y.; Li, J.; Meng, C. Further improvement in ductility induced by the refined hierarchical structures of pearlite. Mater. Sci. Eng. A 2019, 745, 176-184. [CrossRef]

23. Nešić, S. Key issues related to modelling of internal corrosion of oil and gas pipelines-A review. Corros. Sci. 2007, 49, 4308-4338. [CrossRef] 
24. Giarola, J.; Calderón-Hernández, J.; Quispe-Avilés, J.; Avila, J.; Filho, W.B. Hydrogen-induced cracking and corrosion be-havior of friction stir welded plates of API 5L X70 pipeline steel. Int. J. Hydrogen Energy 2021, 46, 28166-28179. [CrossRef]

25. Luo, Q. A New XRD Method to Quantify Plate and Lath Martensites of Hardened Medium-Carbon Steel. J. Mater. Eng. Perform. 2016, 25, 2170-2179. [CrossRef]

26. Basak, M.; Rahman, L.; Ahmed, F.; Biswas, B.; Sharmin, N. The use of X-ray diffraction peak profile analysis to determine the structural parameters of cobalt ferrite nanoparticles using Debye-Scherrer, Williamson-Hall, Halder-Wagner and Size-strain plot: Different precipitating agent approach. J. Alloys Compd. 2021, 9, 162694. [CrossRef]

27. Jiang, W.; Wu, X.; Yang, P.; Xinfu, G. Relationship between the initial $\{100\}$ textures and the shear textures developed in sheet surface during hot rolling of non-oriented silicon steel. Mater. Charact. 2021, 182, 111534. [CrossRef]

28. Pan, H.; Zhang, Z.; Mo, Y.; Xie, J. Strong <001> recrystallization texture component in 6.5 wt $\%$ Si electrical steel thin sheets by secondary cold rolling and annealing. J. Magn. Magn. Mater. 2016, 419, 500-511. [CrossRef]

29. Sha, Y.; Sun, C.; Zhang, F.; Patel, D.; Chen, X.; Kalidindi, S.; Zuo, L. Strong cube recrystallization texture in silicon steel by twin-roll casting process. Acta Mater. 2014, 76, 106-117. [CrossRef]

30. Ohaeri, E.; Eduok, U.; Szpunar, J. Hydrogen related degradation in pipeline steel: A review. Int. J. Hydrogen Energy 2018, 43, 14584-14617. [CrossRef]

31. Shirinzadeh-Dastgiri, M.; Mohammadi, J.; Behnamian, Y.; Eghlimi, A.; Mostafaei, A. Metallurgical investigations and corro-sion behavior of failed weld joint in AISI 1518 low carbon steel pipeline. Eng. Fail. Anal. 2015, 53, 78-96. [CrossRef]

32. Pourazizi, R.; Mohtadi-Bonab, M.; Szpunar, J. Investigation of different failure modes in oil and natural gas pipeline steels. Eng. Fail. Anal. 2020, 109, 104400. [CrossRef]

33. Rahman, K.M.; Mohtadi-Bonab, M.A.; Ouellet, R.; Szpunar, J.; Zhu, N. Effect of electrochemical hydrogen charging on an API X70 pipeline steel with focus on characterization of inclusions. Int. J. Press. Vessel. Pip. 2019, 173, 147-155. [CrossRef]

34. Rahman, K.M.M.; Mohtadi-Bonab, M.A.; Ouellet, R.; Szpunar, J. A Comparative Study of the Role of Hydrogen on Degrada-tion of the Mechanical Properties of API X60, X60SS, and X70 Pipeline Steels. Steel Res. Int. 2019, 90, 1900078. [CrossRef] 